\title{
A Study of the Identification, Fragmentation Mode and Metabolic Pathways of Imatinib in Rats Using UHPLC-Q-TOF-MS/MS
}

\author{
Sijiang Liu ${ }^{1}{ }^{1}$ and Zhaojin Yu $\mathbb{D}^{2,3}$ \\ ${ }^{1}$ Department of Pharmaceutical Sciences, China Medical University-The Queen's University of Belfast Joint College, \\ China Medical University, 77 Puhe Road, Shenyang 110122, China \\ ${ }^{2}$ Department of Pharmacology, School of Pharmacy, China Medical University, Shenyang 110122, China \\ ${ }^{3}$ Liaoning Key Laboratory of Molecular Targeted Anti-Tumor Drug Development and Evaluation, \\ Liaoning Cancer Immune Peptide Drug Engineering Technology Research Center, \\ Key Laboratory of Precision Diagnosis and Treatment of Gastrointestinal Tumors (China Medical University), \\ Ministry of Education, China Medical University, Shenyang 110122, China
}

Correspondence should be addressed to Zhaojin Yu; 20101041@cmu.edu.cn

Received 6 April 2021; Accepted 4 May 2021; Published 24 May 2021

Academic Editor: Antony C. Calokerinos

Copyright ( 2021 Sijiang Liu and Zhaojin Yu. This is an open access article distributed under the Creative Commons Attribution License, which permits unrestricted use, distribution, and reproduction in any medium, provided the original work is properly cited.

\begin{abstract}
In this study, The metabolites, metabolic pathways, and metabolic fragmentation mode of a tyrosine kinase inhibitor- (TKI-) imatinib in rats were investigated. The samples for analysis were pretreated via solid-phase extraction, and the metabolism of imatinib in rats was studied using ultra-high-performance liquid chromatography-quadrupole-time-of-flight mass spectrometry (UHPLC-Q-TOF-MS/MS). Eighteen imatinib metabolites were identified in rat plasma, 21 in bile, 18 in urine, and 12 in feces. Twenty-seven of the above compounds were confirmed as metabolites of imatinib and 9 of them were newly discovered for the first time. Oxidation, hydroxylation, dealkylation, and catalytic dehydrogenation are the main metabolic pathways in phase I. For phase II, the main metabolic pathways were $\mathrm{N}$-acetylation, methylation, cysteine, and glucuronidation binding. The fragment ions of imatinib and its metabolites were confirmed to be produced by the cleavage of the $\mathrm{C}-\mathrm{N}$ bond at the amide bond. The newly discovered metabolite of imatinib was identified by UHPLC-Q-TOF-MS/MS. The metabolic pathway of imatinib and its fragmentation pattern were summarized. These results could be helpful to study the safety of imatinib for clinical use.
\end{abstract}

\section{Introduction}

Imatinib (IM) is the first generation of tyrosine kinase inhibitor $[1,2]$ mainly used for the treatment of chronic, accelerated phase or blast crisis of adult chronic myeloid leukemia with positive Philadelphia chromosome and malignant gastrointestinal stromal tumors that cannot be resected and/or metastasized [3, 4]. IM was first tested in clinical trials in the 1990s and was approved by the US Food and Drug Administration (FDA) at the beginning of this century. Its antitumor mechanism specifically blocks the binding site of adenosine triphosphate (ATP) on tyrosine kinase to inhibit the autophosphorylation and substrate phosphorylation of BCR-ABL target protein. IM could also stabilize the inactive conformation of tyrosine kinase to inhibit its activity, leading to reduced proliferation of chronic myelocytic leukemia (CML) cells and cell apoptosis [5-7]. IM has excellent pharmacokinetic characteristics and its oral bioavailability was reported to be $\geq 98 \%$, with a halflife of 20 hours and peak time ranging from 2 to 4 hours. Its excretion pathway mainly depends on feces and urine [8]. The chemical name of IM is 4-[(4-methyl-1-piperazinyl) methyl]-N-[4-methyl-3-[4-(3-pyridyl)-2-pyrimidinyl] amino] phenyl] benzamide, and its chemical structure is shown in Figure 1.

Most drugs were mainly eliminated from the body after metabolism [9-11]. Metabolism can be understood as the process of converting drugs into their metabolites under the catalysis of enzymes [12]. Drug metabolism may produce one or more active metabolites with the same 


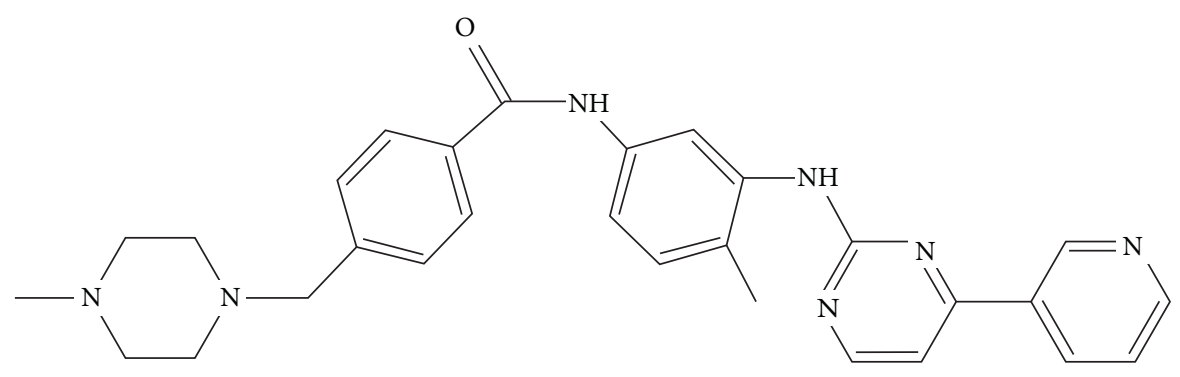

FIgURE 1: The structure of imatinib.

pharmacological effects and targets as the original drug $[13,14]$. Sometimes, it may also generate overactive or toxic metabolites, which may cause serious adverse side-effects [15]. For example, some CML patients developed hepatotoxicity symptoms after using IM, which may be related to one or more metabolites of IM [16]. In addition, studies showed that the main metabolites of IM may be involved in IM resistance [17]. Therefore, to systematically understand the safety of IM for its clinical application, it is necessary to investigate its metabolites. Up to date, researchers have done a lot of work on IM metabolism and achieved reliable results. MarcMarull et al., with the aid of liquid chromatography combined with triple quadrupole mass spectrometer (TSQMS) and linear ion trap mass spectrometer (LTQ-MS), successfully isolated one demethylated metabolite, two hydroxylated metabolites, and three $\mathrm{N}$-oxidation metabolites of IM from microsomes containing cytochrome P450 (CYP) isozymes [18]. Li et al. found 7 cyano metabolites of IM from human liver microsomes (in vitro) and identified their structures [19]. Friedecký et al. have identified 90 metabolites of IM from the plasma of patients with CML [20]. Therefore, a thorough study of the metabolites and metabolic pathways of imatinib will help to use IM safely and rationally. In addition, the study of drug metabolites of IM will help with its clinical efficacy and provide more information for the scientist to develop safer and more effective formulations than the raw materials [21,22].

The purpose of this study was to investigate the metabolism of IM in rats. The metabolites of IM in plasma, bile, urine, and feces were identified using UHPLC-Q-TOF-MS/ MS. The metabolic pathways of phases I and II and the fragmentation pattern of metabolites were also summarized.

\section{Materials and Methods}

2.1. Chemicals and Reagents. Imatinib (purity, $\geq 99.0 \%$ ) was obtained from Shanghai Macklin Biochemical Technology Co., Ltd., China. HPLC grade acetonitrile and formic acid were purchased from Fisher Scientific (Fair Lawn, NJ, USA). Methanol (analytical or HPLC grade) was procured from Yuwang Industrial Co., Ltd. (Shandong, China). Purified water was provided by Wahaha Group Co., Ltd. (Hangzhou, China).

2.2. Animal Experiments. Male Sprague-Dawley (SD) rats ( $n=18$, weighing $220-250 \mathrm{~g}, 12-14$ weeks old) were provided by the Experimental Animal Center of Shenyang
Pharmaceutical University (Shenyang, China). The SD rats were fed in metabolic cages for at least 3 days and fasted for $12 \mathrm{~h}$ before the experiments. All experiments in vivo were conducted under the guidelines of the administration of experimental animals in China.

IM $(50 \mathrm{mg} / \mathrm{mL})$ was dissolved in $0.5 \%$ carboxymethyl cellulose sodium (CMC-Na) aqueous solution. After administering IM solution at a dose of $50 \mathrm{mg} / \mathrm{kg}$, the rats were randomly divided into three groups (six rats in each group).

Group I was for taking the plasma samples. The blood was taken from the ophthalmic veins at time points at $0.5,1$, $2,4,8$, and $12 \mathrm{~h}$ after oral administration of IM, and then the blood collected in heparinized tubes was centrifuged immediately at $5000 \mathrm{rpm}$ for $10 \mathrm{~min}$ to obtain the plasma. For Group II (bile samples), the rats were anesthetized with urethane solution $(0.05 \mathrm{~mL} / 10 \mathrm{~g})$. Duct cannulation operation was performed to collect blank bile first, and the rats were allowed to recover from anesthesia before drug administration. The samples were continuously collected but samples were divided according to the period of $0-4,4-8$, $8-12,12-24$, and $24-48 \mathrm{~h}$. Group III was used for obtaining the urine and feces samples. The rats were kept in metabolic cages individually and orally given IM, and then, the samples were collected at different time intervals of $0-4,4-8,8-12$, $12-24$, and $24-48 \mathrm{~h}$. All the blank samples of each group were collected before oral administration of IM. All collected samples were stored at $-80^{\circ} \mathrm{C}$ until further treatment.

2.3. Sample Pretreatment. Pretreatment of plasma: $200 \mu \mathrm{L}$ of plasma sample was extracted using $600 \mathrm{uL}$ of methanol and then vortexed for $1 \mathrm{~min}$ to precipitate the proteins. After centrifugation at $12000 \mathrm{rpm}$ for $10 \mathrm{~min}$ at $4^{\circ} \mathrm{C}$, the supernatant was transferred into a clean tube and dried under nitrogen gas at $40^{\circ} \mathrm{C}$.

Pretreatment of feces: feces sample $(0.2 \mathrm{mg})$ was added to methanol $(2 \mathrm{~mL})$, then vortexed for $2 \mathrm{~min}$, followed by sonication for $30 \mathrm{~min}$, and vortexed again for another $2 \mathrm{~min}$. After the mixture was centrifuged $(13000 \mathrm{rpm}, 10 \mathrm{~min})$ at $4^{\circ} \mathrm{C}$, the supernatant was collected and dried with nitrogen flow at $40^{\circ} \mathrm{C}$.

Pretreatment of urine and bile: the solid-phase extraction cartridges (Angela Bond Elut C-18, $1 \mathrm{~g}$ ) were activated via duplicated wash using water $(1 \mathrm{~mL})$, followed by methanol (1 mL). After centrifugation (13000 rpm) for $5 \mathrm{~min}$, the supernatant was filtrated through a $0.22 \mu \mathrm{m}$ membrane filter, followed by further purification $(1 \mathrm{~mL}$ of 
the filtered sample) with a solid-phase extraction cartridge at a flow rate of $30 \mathrm{drops} \cdot \mathrm{min}^{-1}$. The cartridges were washed with water $(1 \mathrm{~mL})$ first and then washed for another 3 times using $1 \mathrm{~mL}$ of $0.1 \%$ formic acid in methanol. The eluent of $0.1 \%$ formic acid in methanol was collected and dried with nitrogen flow at $40^{\circ} \mathrm{C}$.

Before analysis, all the pretreatment samples have been dried with nitrogen, and the residues were reconstituted with $200 \mu \mathrm{L}$ of a mixed solvent of acetonitrile and $0.1 \%$ formic acid in water in a ratio of 10:90 (v/v) and then sonicated for $10 \mathrm{~min}$ before centrifugation $(12000 \mathrm{rpm})$ at $4^{\circ} \mathrm{C} .3 \mu \mathrm{L}$ of the supernatant was finally injected for UHPLCQ-TOF-MS/MS analysis.

2.4. Instruments and Conditions. The chromatographic separation was carried out using a ACQUITY UHPLCTM BEH C18 column $(100 \times 2.1 \mathrm{~mm}, 1.7 \mu \mathrm{m})$. Mobile phase A was an aqueous buffer containing $0.1 \%$ formic acid and $10 \mathrm{mmol} / \mathrm{L}$ ammonium acetate and $\mathrm{B}$ was $0.1 \%$ formic acid in acetonitrile. The gradient elution program was optimized listed as follows: $10-25 \% \mathrm{~B}$ from 0 to $9.5 \mathrm{~min}, 25-35 \% \mathrm{~B}$ from 9.5 to $12.5 \mathrm{~min}, 35-90 \% \mathrm{~B}$ from 12.5 to $20.0 \mathrm{~min}$, and $90-10 \%$ B from 22.0 to $22.1 \mathrm{~min}$. Flow rate was $0.3 \mathrm{~mL} / \mathrm{min}$; temperature, $40^{\circ} \mathrm{C}$; injection volume, $3 \mu \mathrm{L}$.

Mass spectrometry detection was performed using an $\mathrm{AB}$ SCIEX X500R UPLC-Q/TOF-MS (AB SCIEX, Framingham, MA, USA). Mass spectrum acquisition was in positive electrospray ionization mode and the conditions used were as follows: the pressure of the nebulizer gas (gas 1), the heater gas (gas 2), and the curtain gas was set to 55,55 , and $35 \mathrm{psi}$, respectively; ion source temperature was $600^{\circ} \mathrm{C}$. TOF-MS/ MS parameter settings are as follows: scanning range, $\mathrm{m} / \mathrm{z}$ 50 1000; collision gas, $7 \mathrm{psi}$; ion spray voltage, $5.5 \mathrm{kV}$; declustering potential (DP), $80 \mathrm{~V}$; the collision energy (CE), $10 \mathrm{~V}$; TOF-MS/MS, $\mathrm{m} / z$ 50-1000; ion spray voltage, $5.5 \mathrm{kV}$; declustering potential (DP), $80 \mathrm{~V}$; the collision energy (CE), from 20 to $50 \mathrm{~V}$; accumulation time, $25 \mathrm{~min}$. Apply $\mathrm{AB}$ SCIEX OS for processing. In the experiment, the CDS automatic calibration system was used to calibrate the experimental data collection.

\section{Results and Discussion}

The MS/MS spectrum of IM standard is shown in Figure 2; the ion at $m / z 394$ was formed after the cleavage of the 4methyl-1-piperazinyl group on benzamide on the phenyl group of 2-aniline pyrimidine, and the ion at $\mathrm{m} / \mathrm{z} 394$ generated $\mathrm{m} / \mathrm{z} 378$ by the loss of $\mathrm{O}$ of the benzoylamino group. The ion at $m / z 217$ was formed after the cleavage of the amide part of benzamide, and the ion at $\mathrm{m} / \mathrm{z} 217$ generated $\mathrm{m} / z 174$ by RDA (Reverse-Diels-Alder reaction) cleavage reaction. As shown in Figure 3, the analytes eluted at $11.17 \mathrm{~min}$, with the molecular ion $[\mathrm{M}+\mathrm{H}]^{+}$of $\mathrm{m} / \mathrm{z}$ 494.2648, were consistent with the ion at $m / z 394,378,217$, and 174 of the IM reference standard, indicating that IM (M0) was detected in plasma, bile, urine, and feces of rat. M3, M9, M11, M17, M20, M22-23, and M26-27 were newly discovered metabolites in this study.
3.1. Metabolite Analysis in Plasma. Compared with blank samples, there were 6 newly identified metabolites (M11, M17, M22-M23, and M26-M27) in the plasma together with twelve previously reported ones (M5-M7, M10, M12 -M16, M18-M19, and M21). The extracted ion chromatograms of all plasma metabolites are shown in Figure 4. The retention times, excimer ions, and secondary fragment ions (see Table 1) were analyzed together, and the metabolite structures were inferred based on the metabolic patterns of the IM (Figure 5). Moreover, if the structure of some metabolites is different from IM, the structural fracture mode of other known metabolites is used for analysis.

Metabolites of M6, M7, M10, M14, and M18 $\left(\mathrm{C}_{29} \mathrm{H}_{32} \mathrm{~N}_{7} \mathrm{O}_{2}\right)$ were detected in MS/MS spectra at $8.19 \mathrm{~min}$, $11.54 \mathrm{~min}, 10.37 \mathrm{~min}, 9.46 \mathrm{~min}$, and $8.81 \mathrm{~min}$, respectively. These 5 metabolites were $16 \mathrm{Da}(-\mathrm{OH})$ higher than IM. They had similar MS/MS spectra and produced protonated molecule ions $[\mathrm{M}+\mathrm{H}]^{+}$at $\mathrm{m} / z$ 510.2611, $\mathrm{m} / \mathrm{z} 510.2598, \mathrm{~m} / \mathrm{z}$ $510.2610, \mathrm{~m} / z$ 510.2611, and $\mathrm{m} / z$ 510.2610. The ions at $\mathrm{m} / \mathrm{z}$ 410 were generated via the broken chemical bond between the methyl groups on the $\mathrm{C}_{4}$ position of the benzene ring that were substituted by hydroxyl groups and piperazine group. The remaining fragment ions are related to the fragmentation of the benzamide group. The presence of $\mathrm{m} / z 277$ resulted from the fracture of the benzamide group $\mathrm{N}$ and hydroxyl substituted 4-methyl-3-[4-(3-pyridyl)-2-pyrimidine. After the amide bond was disrupted, the ion at $\mathrm{m} / z 217$ was detected in MS/MS spectra. The loss of $\mathrm{C}=\mathrm{O}(\mathrm{m} / z$ 217) results in the emergence of $\mathrm{m} / z$ 189; then, $\mathrm{m} / z 111$ and $\mathrm{m} / z 410$ are two fragments produced by a fracture occurring in the same location, and the comprehensive analysis indicates that M6 is a hydroxyl metabolite of IM (substituted at 4-methyl-3-[4-(3pyridine)-2-pyrimidine). However, the $\mathrm{MS}^{2}$ spectra of M7 were observed with one more fragment ion $(\mathrm{m} / z$ 394) than M6 $(\mathrm{m} / \mathrm{z} 410)$ due to loss of $\mathrm{O}$ atom at $\mathrm{N}$-oxidized metabolite. It was speculated that M7 may be the $\mathrm{N}$-oxidation of 4methyl-3-[4-(3-pyridine)-2-pyrimidine in the IM structure. Compared to M6, M10, and M14, it almost went through the same fragmentation, but the $m / z 277$ fragment ion was not observed, suggesting that there was more $\mathrm{N}$ atom substitution on the benzamide group at the hydroxyl substitution position. Therefore, M10 and M14 may be N-oxidized or hydroxyl substituted metabolites of IM (substitution occurs on the N-4-methyl-3-[4-(3-pyridine)-2-pyrimidine structure). The $m / z 380$ fragment ion of M18 was the product of deamination of $\mathrm{CH}_{2}$ from one molecule of benzamide by the $\mathrm{m} / \mathrm{z} 394$ fragment ions, and the other fragment ions were degraded in the same manner as M6. It is presumed that M18 may be an N-oxidized metabolite of IM (occurring on the structure of 4-methyl-3-[4-(3-pyridine)-2-pyrimidine). Among the remaining metabolites, five of them (M13, M15, M16, M21, and M23) had molecular weights that differed from IM by $14 \mathrm{Da}$. Metabolites M13 and M21 $\left(\mathrm{C}_{29} \mathrm{H}_{30} \mathrm{~N}_{7} \mathrm{O}_{2}\right)$ were observed in MS/MS spectra at $10.08 \mathrm{~min}$ and $12.06 \mathrm{~min}$; then, they created protonated molecule ions $[\mathrm{M}+\mathrm{H}]^{+}$at $\mathrm{m} / \mathrm{z}$ 508.2447 and $m / z 508.2443$, respectively; they were all $14 \mathrm{Da}$ higher than IM. After the $\mathrm{C}_{4}$ methyl on the benzene ring of 2anilinopyrimidine breaks, the site forms a five-membered ring with the $\mathrm{C}_{1}-\mathrm{N}$ of the pyrimidine ring. Then, the chemical 


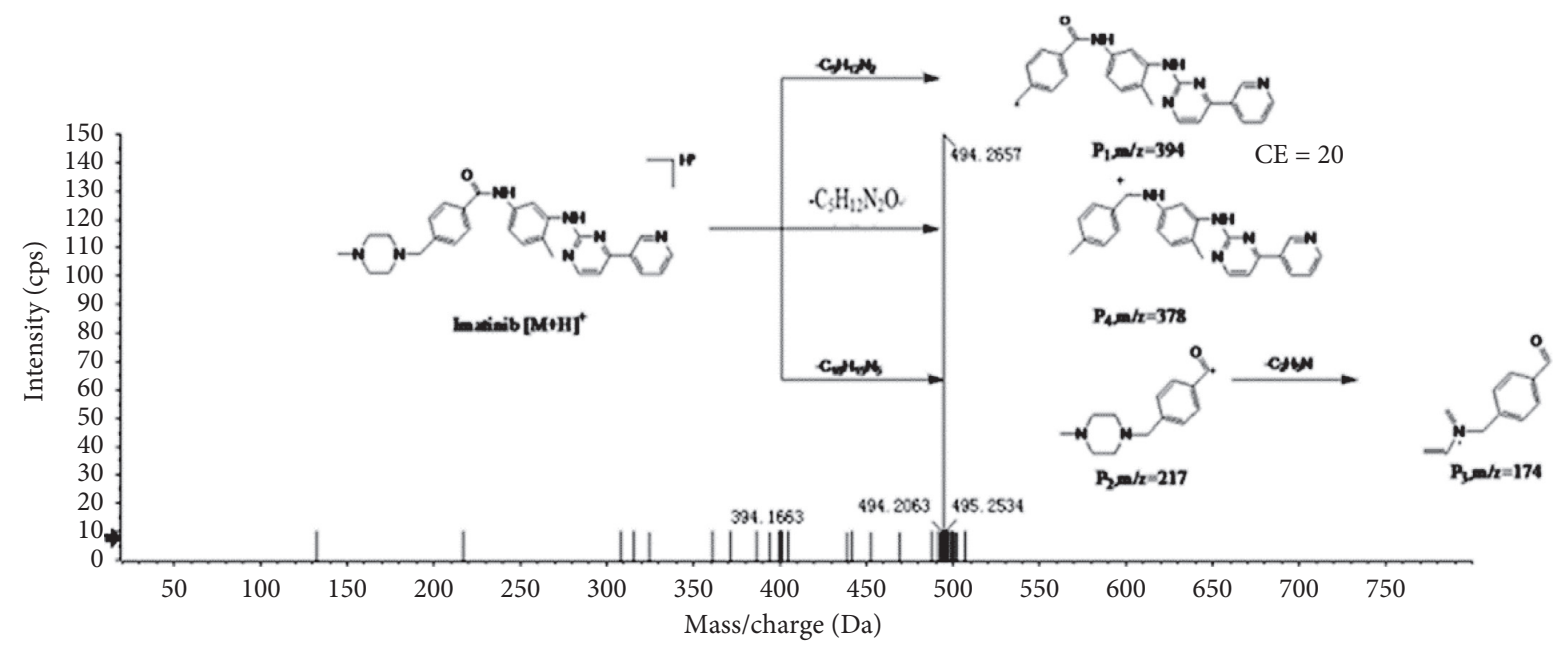

(a)

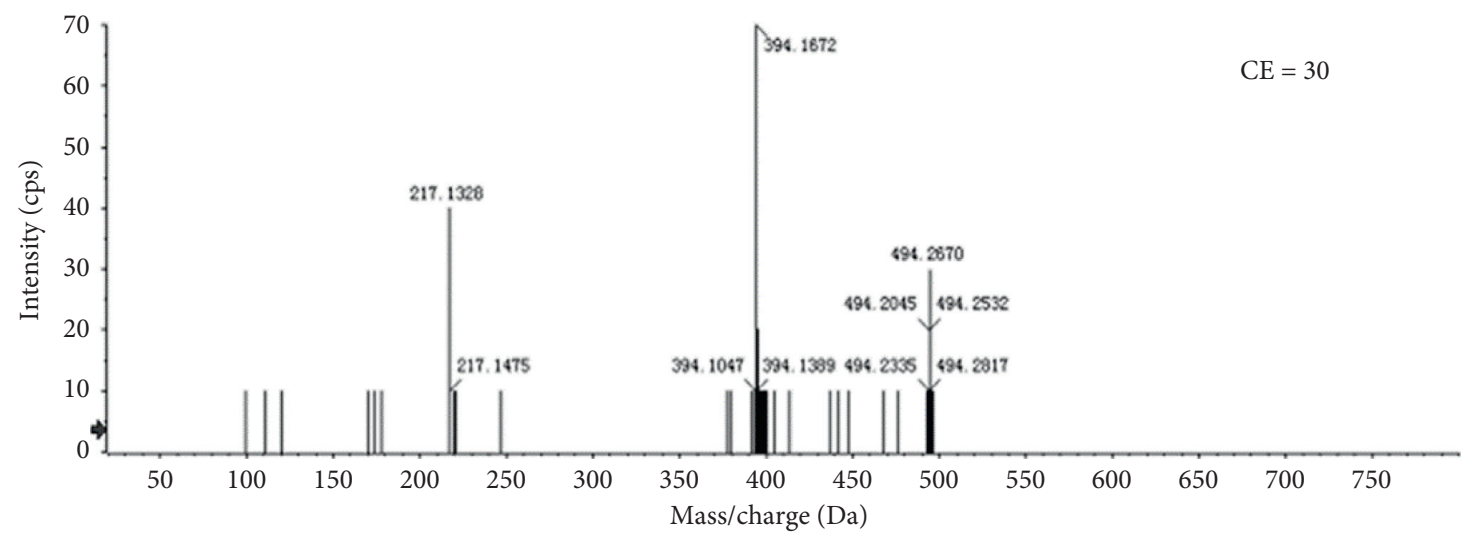

(b)

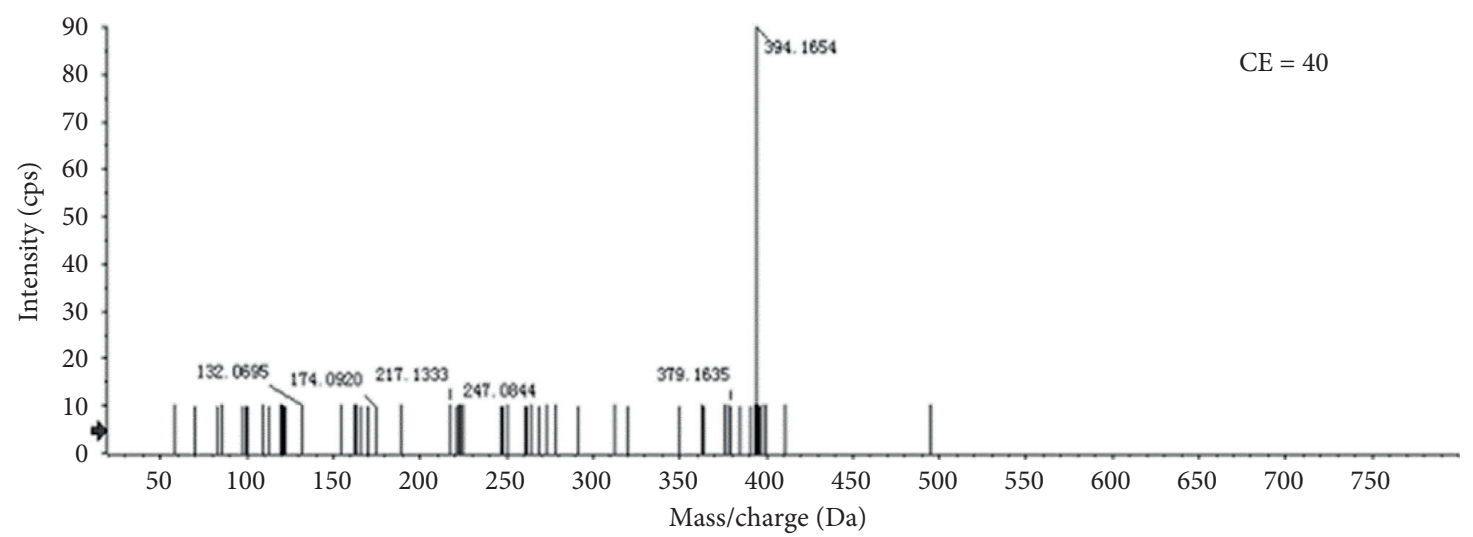

(c)

Figure 2: Continued. 


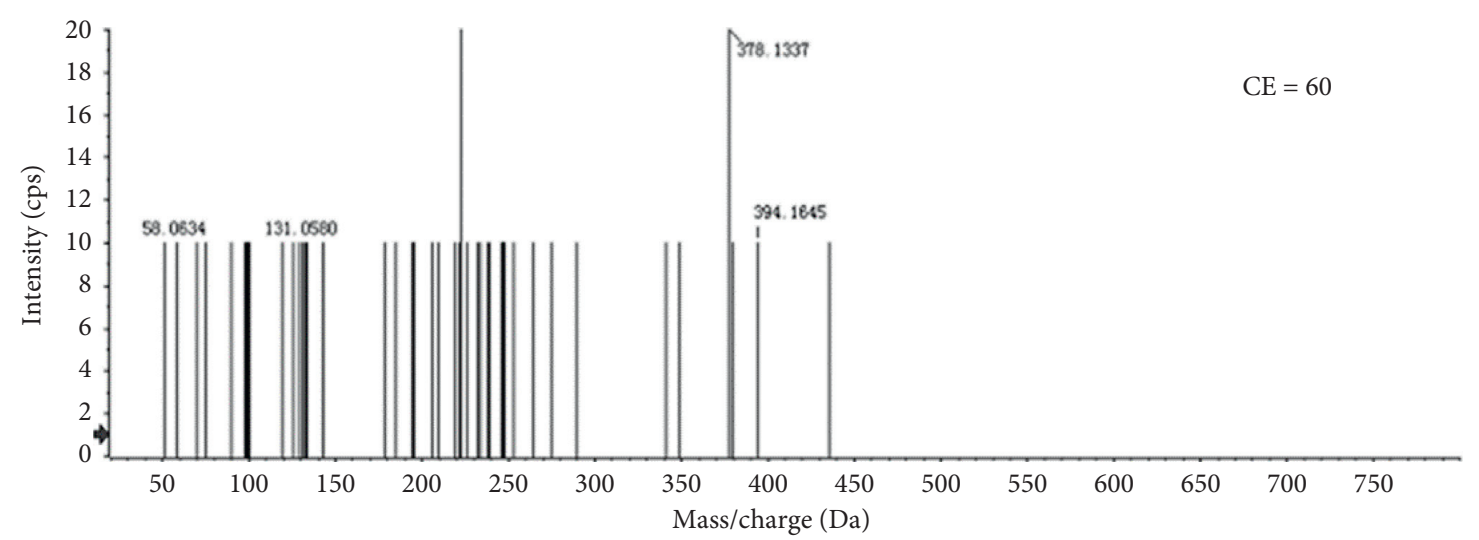

(d)

FIgURE 2: In ESI positive ion mode, different energy collision spectra of $[\mathrm{M}+\mathrm{H}]^{+}$of $\mathrm{IM}$ and proposed fragmentation pattern of IM.
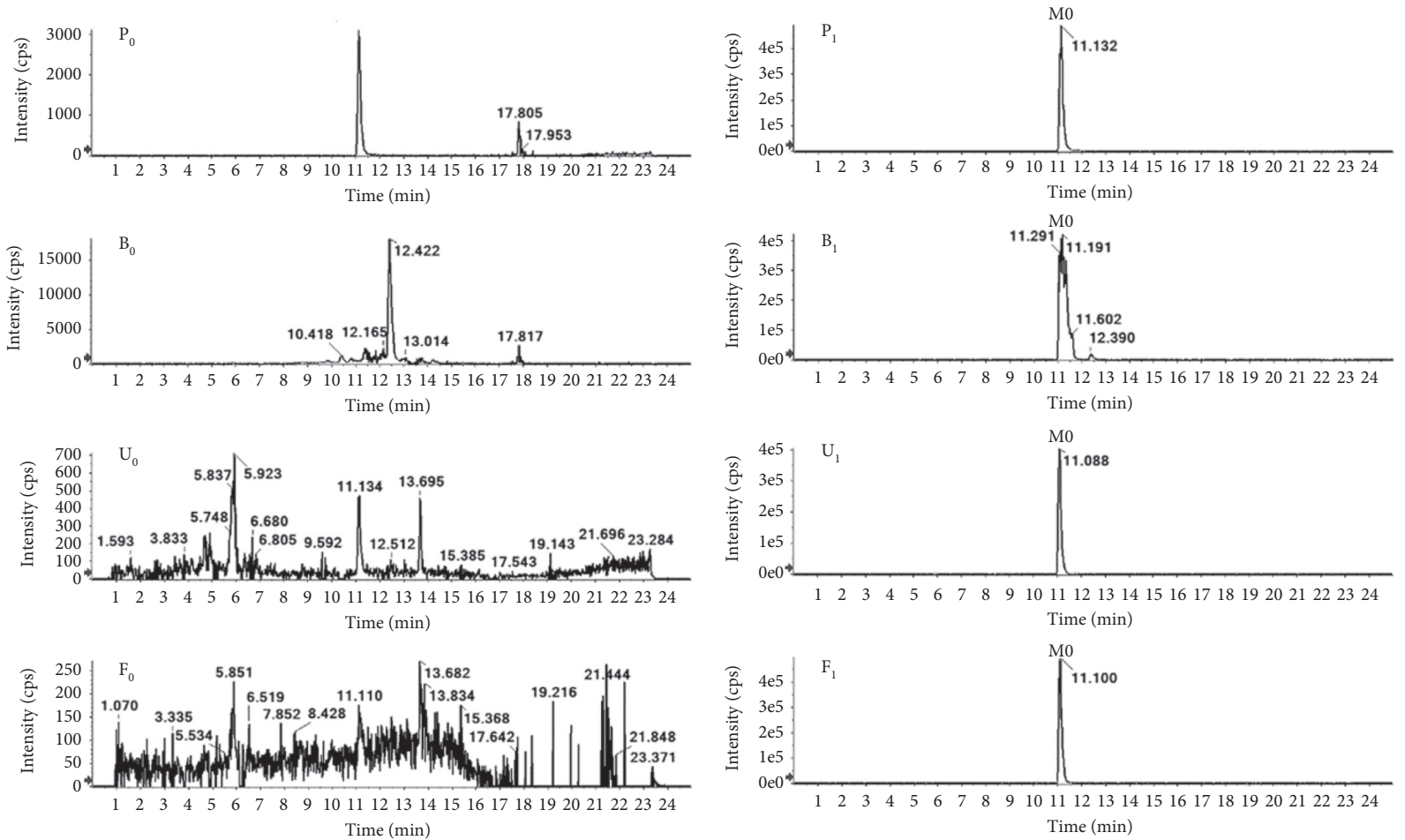

(a)

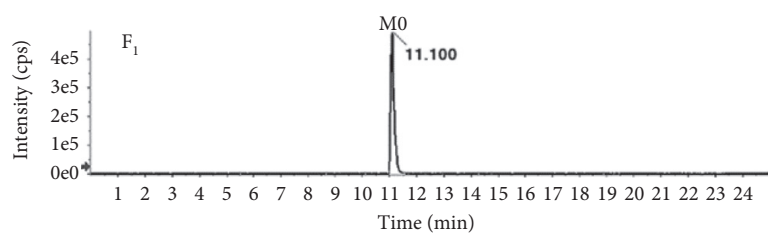

(b)

Figure 3: Base peak ion chromatograms of biological samples in positive ion mode. $P_{0}, B_{0}, U_{0}$, and $F_{0}$ represent blank samples of plasma, bile, urine, and feces from rats; $\mathrm{P}_{1}, \mathrm{~B}_{1}, \mathrm{U}_{1}$, and $\mathrm{F}_{1}$ represent plasma, bile, urine, and feces samples from rats after oral administration of IM.

bonds between $\mathrm{C}_{1}$ and $\mathrm{N}$ breaks, $m / z 247$, and fragment ions are generated. The fragment ion at $m / z 222$ was generated by the fracture of $\mathrm{C}_{1}$ and $\mathrm{C}_{6}, \mathrm{C}_{4}$, and $\mathrm{C}_{5}$ in the fragment ion structure of $m / z \quad 247$ and simultaneously intramolecular proton migration rearrangement. The fragment ion at $\mathrm{m} / z$ 231 was generated after the amide bond fracture of carbonylsubstituted IM, and the ionic fracture mode of other fragments was the same as that of M6. M13 and M21 are the IM metabolites of the carbonylation of 4-methylpiperazine rings.

Metabolites M16 $\left(\mathrm{C}_{29} \mathrm{H}_{29} \mathrm{~N}_{7} \mathrm{O}_{2}\right)$ and $\mathrm{M} 23\left(\mathrm{C}_{30} \mathrm{H}_{34} \mathrm{~N}_{7} \mathrm{O}\right)$, showing the molecular ions $[\mathrm{M}+\mathrm{H}]^{+}$at $m / z 508.2454$ and $\mathrm{m} / z$ 508.2817, were eluted at $10.75 \mathrm{~min}$ and $12.50 \mathrm{~min}$, and they were $14 \mathrm{Da}$ more than that of IM. For the prototype drug, M0, N-demethylated amide bond connecting to the benzene ring broke and formed $\mathrm{m} / z 203$ fragment ion of M16. The fragment of $m / z 203$ further lost one $\mathrm{CO}$ and generated the fragment ion of $m / z$ 175. The other fragment ions share the same metabolite pathway as the above. Therefore, the metabolite is considered to be the IM metabolite of carbonylation of N-methyl. The $\mathrm{m} / z 408$ fragment ion of M23 was the M0 methylation followed by the removal of the 4-methyl-1-piperazinyl group, and it is presumed to 

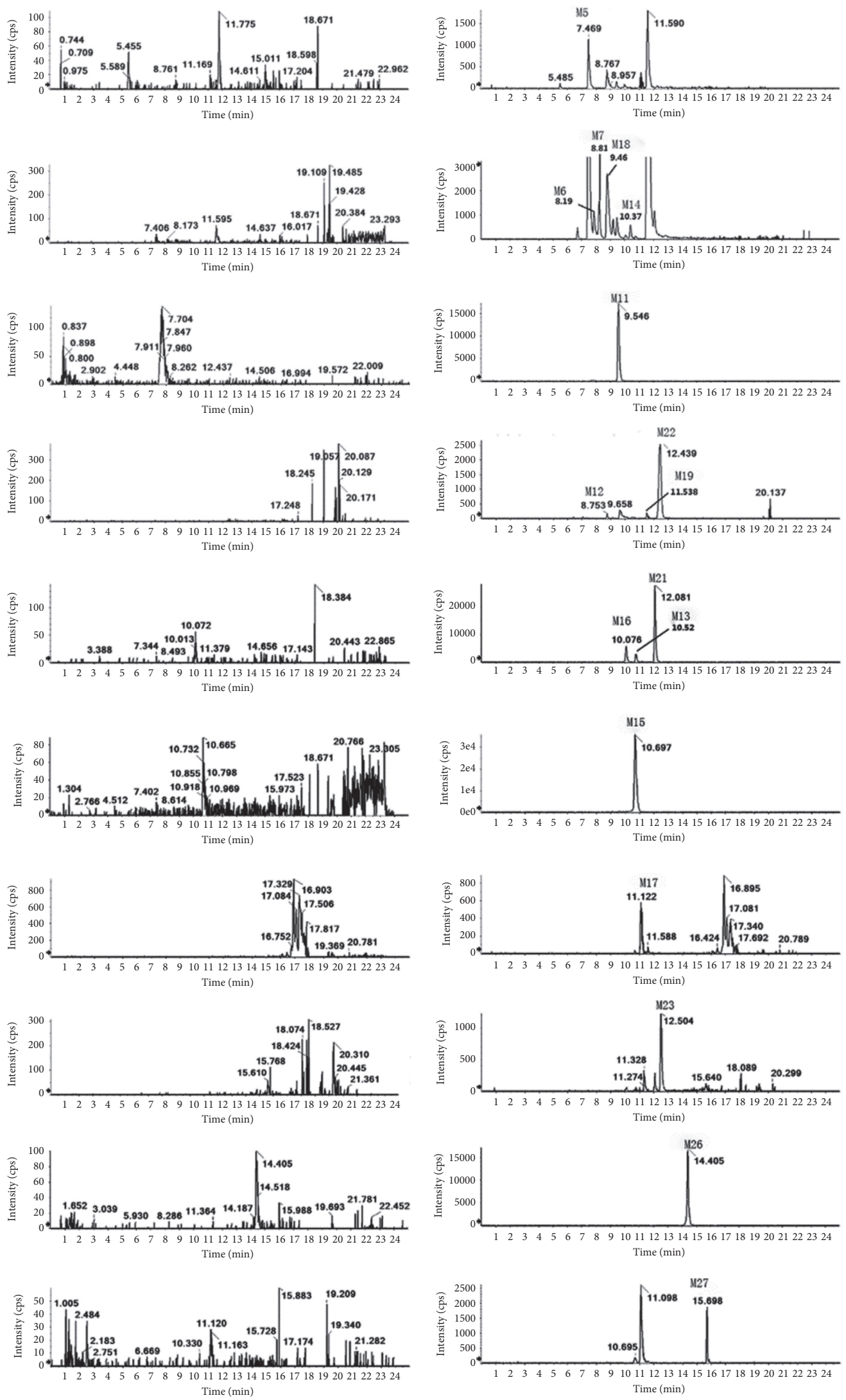

(a)

(b)

FIGURE 4: Extracted ion chromatograms (XIC) for metabolites in rats: (a) in blank plasma sample; (b) in plasma sample after an oral administration of IM. 
TABLE 1: Chromatographic retention times, precursor ions, and key fragments of IM and its metabolites in rat plasma, bile, urine, and feces sample.

\begin{tabular}{|c|c|c|c|c|c|c|c|c|c|c|c|}
\hline No. & $\begin{array}{c}\text { Formula of } \\
{[\mathrm{M}+\mathrm{H}]^{+} \text {ion }}\end{array}$ & MS data & $\begin{array}{l}\text { Error } \\
(\mathrm{ppm})\end{array}$ & $\begin{array}{c}t_{R} \\
(\mathrm{~min}) \\
\end{array}$ & MS/MS data & Plasma & Bile & Urine & Feces & No. & $\begin{array}{c}\text { Formula of } \\
{[\mathrm{M}+\mathrm{H}]^{+} \text {ion }}\end{array}$ \\
\hline M1 & $\mathrm{C}_{29} \mathrm{H}_{30} \mathrm{~N}_{7} \mathrm{O}_{3}{ }^{+}$ & 524.2414 & 1.4 & 6.36 & $119,231,392,506$ & - & + & - & - & M1 & $\mathrm{C}_{29} \mathrm{H}_{30} \mathrm{~N}_{7} \mathrm{O}_{3}{ }^{+}$ \\
\hline M2 & $\mathrm{C}_{35} \mathrm{H}_{40} \mathrm{~N}_{7} \mathrm{O}_{8}^{+}$ & 686.2936 & 0.4 & 6.45 & $217,410,510$ & - & + & + & - & M2 & $\mathrm{C}_{35} \mathrm{H}_{40} \mathrm{~N}_{7} \mathrm{O}_{8}^{+}$ \\
\hline M3 & $\mathrm{C}_{15} \mathrm{H}_{22} \mathrm{~N}_{3} \mathrm{O}_{2}^{+}$ & 276.1708 & 0.7 & 6.78 & 147,258 & - & + & + & - & M3 & $\mathrm{C}_{15} \mathrm{H}_{22} \mathrm{~N}_{3} \mathrm{O}_{2}{ }^{+}$ \\
\hline M4 & $\mathrm{C}_{29} \mathrm{H}_{30} \mathrm{~N}_{7} \mathrm{O}_{3}^{+}$ & 524.2406 & -0.1 & 7.22 & $203,231,392,410,506$ & - & + & + & - & M4 & $\mathrm{C}_{29} \mathrm{H}_{30} \mathrm{~N}_{7} \mathrm{O}_{3}^{+}$ \\
\hline M5 & $\mathrm{C}_{30} \mathrm{H}_{32} \mathrm{~N}_{6} \mathrm{O}^{+}$ & 492.2508 & 0.3 & 7.47 & $217,275,392$ & + & + & + & + & M5 & $\mathrm{C}_{30} \mathrm{H}_{32} \mathrm{~N}_{6} \mathrm{O}^{+}$ \\
\hline M6 & $\mathrm{C}_{29} \mathrm{H}_{32} \mathrm{~N}_{7} \mathrm{O}_{2}^{+}$ & 510.2611 & -0.2 & 8.19 & $111,217,189,277,410$ & + & + & + & - & M6 & $\mathrm{C}_{29} \mathrm{H}_{32} \mathrm{~N}_{7} \mathrm{O}_{2}^{+}$ \\
\hline M7 & $\mathrm{C}_{29} \mathrm{H}_{32} \mathrm{~N}_{7} \mathrm{O}_{2}^{+}$ & 510.261 & -0.4 & 8.81 & $277,380,394,410$ & + & + & + & + & M7 & $\mathrm{C}_{29} \mathrm{H}_{32} \mathrm{~N}_{7} \mathrm{O}_{2}^{+}$ \\
\hline M8 & $\mathrm{C}_{29} \mathrm{H}_{30} \mathrm{~N}_{7} \mathrm{O}_{3}^{+}$ & 524.2412 & 1 & 9.1 & $119,203,231,410$ & - & + & - & - & M8 & $\mathrm{C}_{29} \mathrm{H}_{30} \mathrm{~N}_{7} \mathrm{O}_{3}{ }^{+}$ \\
\hline M9 & $\mathrm{C}_{24} \mathrm{H}_{23} \mathrm{~N}_{6} \mathrm{O}^{+}$ & 411.1931 & 0.8 & 9.41 & $134,247,264,394$ & - & + & - & - & M9 & $\mathrm{C}_{24} \mathrm{H}_{23} \mathrm{~N}_{6} \mathrm{O}^{+}$ \\
\hline M10 & $\mathrm{C}_{29} \mathrm{H}_{32} \mathrm{~N}_{7} \mathrm{O}_{2}^{+}$ & 510.2611 & -0.2 & 9.46 & $111,189,217,410$ & + & - & + & + & M10 & $\mathrm{C}_{29} \mathrm{H}_{32} \mathrm{~N}_{7} \mathrm{O}_{2}^{+}$ \\
\hline M11 & $\mathrm{C}_{18} \mathrm{H}_{17} \mathrm{~N}_{5} \mathrm{O}^{+}$ & 320.1498 & -2.5 & 9.5 & 261,278 & + & + & - & + & M11 & $\mathrm{C}_{18} \mathrm{H}_{17} \mathrm{~N}_{5} \mathrm{O}^{+}$ \\
\hline M12 & $\mathrm{C}_{29} \mathrm{H}_{31} \mathrm{~N}_{7} \mathrm{O}_{3}^{+}$ & 524.2409 & 0.6 & 9.76 & $99,217,290,506$ & + & + & + & + & M12 & $\mathrm{C}_{29} \mathrm{H}_{31} \mathrm{~N}_{7} \mathrm{O}_{3}{ }^{+}$ \\
\hline M13 & $\mathrm{C}_{29} \mathrm{H}_{30} \mathrm{~N}_{7} \mathrm{O}_{2}^{+}$ & 508.2447 & -1.6 & 10.08 & $203,222,231,247,394$ & + & + & + & + & M13 & $\mathrm{C}_{29} \mathrm{H}_{30} \mathrm{~N}_{7} \mathrm{O}_{2}{ }^{+}$ \\
\hline M14 & $\mathrm{C}_{29} \mathrm{H}_{32} \mathrm{~N}_{7} \mathrm{O}_{2}^{+}$ & 510.261 & -0.3 & 10.37 & $111,217,410$ & + & - & - & - & M14 & $\mathrm{C}_{29} \mathrm{H}_{32} \mathrm{~N}_{7} \mathrm{O}_{2}^{+}$ \\
\hline M15 & $\mathrm{C}_{28} \mathrm{H}_{30} \mathrm{~N}_{7} \mathrm{O}^{+}$ & 480.2505 & -0.2 & 10.52 & $119,203,222,394$ & + & + & + & + & M15 & $\mathrm{C}_{28} \mathrm{H}_{30} \mathrm{~N}_{7} \mathrm{O}^{+}$ \\
\hline M16 & $\mathrm{C}_{29} \mathrm{H}_{29} \mathrm{~N}_{7} \mathrm{O}_{2}^{+}$ & 508.2454 & -0.3 & 10.75 & $175,203,222,231,247,000$ & + & + & - & + & M16 & $\mathrm{C}_{29} \mathrm{H}_{29} \mathrm{~N}_{7} \mathrm{O}_{2}^{+}$ \\
\hline M17 & $\mathrm{C}_{26} \mathrm{H}_{24} \mathrm{~N}_{6} \mathrm{O}^{+}$ & 437.2082 & -0.6 & 11.09 & $160,290,379,394$ & + & - & - & - & M17 & $\mathrm{C}_{26} \mathrm{H}_{24} \mathrm{~N}_{6} \mathrm{O}^{+}$ \\
\hline M18 & $\mathrm{C}_{29} \mathrm{H}_{32} \mathrm{~N}_{7} \mathrm{O}_{2}^{+}$ & 510.2598 & -2.9 & 11.54 & $189,277,394$ & + & + & + & + & M18 & $\mathrm{C}_{29} \mathrm{H}_{32} \mathrm{~N}_{7} \mathrm{O}_{2}^{+}$ \\
\hline M19 & $\mathrm{C}_{29} \mathrm{H}_{30} \mathrm{~N}_{7} \mathrm{O}_{3}^{+}$ & 524.2397 & -1.8 & 11.54 & $189,217,394,494$ & + & + & - & - & M19 & $\mathrm{C}_{29} \mathrm{H}_{30} \mathrm{~N}_{7} \mathrm{O}_{3}^{+}$ \\
\hline M20 & $\mathrm{C}_{24} \mathrm{H}_{20} \mathrm{~N}_{5} \mathrm{O}_{3}^{+}$ & 426.1582 & 4.9 & 11.83 & $133,277,408$ & - & + & + & - & M20 & $\mathrm{C}_{24} \mathrm{H}_{20} \mathrm{~N}_{5} \mathrm{O}_{3}^{+}$ \\
\hline M21 & $\mathrm{C}_{29} \mathrm{H}_{30} \mathrm{~N}_{7} \mathrm{O}_{2}^{+}$ & 508.2443 & -2.5 & 12.06 & $222,231,247,394$ & + & + & + & + & M21 & $\mathrm{C}_{29} \mathrm{H}_{30} \mathrm{~N}_{7} \mathrm{O}_{2}^{+}$ \\
\hline M22 & $\mathrm{C}_{29} \mathrm{H}_{29} \mathrm{~N}_{7} \mathrm{O}_{3}^{+}$ & 524.2396 & -2.1 & 12.42 & $219,247,394,478$ & + & - & + & - & M22 & $\mathrm{C}_{29} \mathrm{H}_{29} \mathrm{~N}_{7} \mathrm{O}_{3}^{+}$ \\
\hline M23 & $\mathrm{C}_{30} \mathrm{H}_{34} \mathrm{~N}_{7} \mathrm{O}^{+}$ & 508.2817 & -0.5 & 12.5 & $119,189,217,264,408$ & + & - & + & - & M23 & $\mathrm{C}_{30} \mathrm{H}_{34} \mathrm{~N}_{7} \mathrm{O}^{+}$ \\
\hline M24 & $\mathrm{C}_{32} \mathrm{H}_{33} \mathrm{~N}_{8} \mathrm{O}_{3} \mathrm{~S}^{+}$ & 609.2383 & -1.3 & 12.68 & $171,215,394,478,565$ & - & + & + & + & M24 & $\mathrm{C}_{32} \mathrm{H}_{33} \mathrm{~N}_{8} \mathrm{O}_{3} \mathrm{~S}^{+}$ \\
\hline M25 & $\mathrm{C}_{24} \mathrm{H}_{20} \mathrm{~N}_{5} \mathrm{O}_{3}^{+}$ & 426.1568 & 1.7 & 13.2 & $149,261,408$ & - & + & + & + & M25 & $\mathrm{C}_{24} \mathrm{H}_{20} \mathrm{~N}_{5} \mathrm{O}_{3}{ }^{+}$ \\
\hline M26 & $\mathrm{C}_{24} \mathrm{H}_{19} \mathrm{~N}_{5} \mathrm{O}_{2}^{+}$ & 410.1613 & 0.4 & 14.17 & $133,261,392$ & + & + & + & - & M26 & $\mathrm{C}_{24} \mathrm{H}_{19} \mathrm{~N}_{5} \mathrm{O}_{2}^{+}$ \\
\hline M27 & $\mathrm{C}_{24} \mathrm{H}_{21} \mathrm{~N}_{5} \mathrm{O}^{+}$ & 396.1818 & -0.6 & 15.7 & 119,378 & + & - & - & - & M27 & $\mathrm{C}_{24} \mathrm{H}_{21} \mathrm{~N}_{5} \mathrm{O}^{+}$ \\
\hline
\end{tabular}

be an N-methylation reaction on the amino group of the benzamide group or the amino group of 2 -aniline on the pyrimidine ring. The fragment ion at $m / z 264$ was generated by the breakage of the amide bond after the breakage of the methyl group of $\mathrm{C}_{4}$ on the benzene ring of 2-anilinopyrimidine and the formation of a five-membered ring at this site with $\mathrm{C}_{1}-\mathrm{N}$ of the pyrimidine ring. Other fragment ions were also broken in the same way as above. Therefore, it was predicted that M23 is an amino group from the benzamide group of IM or an $\mathrm{N}$-methylated metabolite from the amino group of 2-aniline on the pyrimidine ring.

Metabolite M15 $\left(\mathrm{C}_{28} \mathrm{H}_{30} \mathrm{~N}_{7} \mathrm{O}\right)$, with a $[\mathrm{M}+\mathrm{H}]^{+}$of $\mathrm{m} / z$ 480.2505, was eluted at $10.52 \mathrm{~min}$, which was $14 \mathrm{Da}$ less than that of IM. M15 had the same fragment ion of $m / z 394$ as the above metabolites and two new fragments. One $(\mathrm{m} / z 119)$ formed via the separation of the carbonyl group from the benzene ring. The breakage of the amide bond to the benzene ring after N-demethylation of IM yields fragment ion of $\mathrm{m} / z$ 203 , and the $m / z 222$ fragment ion was the methyl group of $\mathrm{C}_{4}$ from the benzene ring of 2-anilinopyrimidine after the breakage of this site and the $\mathrm{C}_{1}-\mathrm{N}$ of the pyrimidine ring to form a five-membered ring. $\mathrm{C}_{1}, \mathrm{C}_{6}, \mathrm{C}_{4}$, and $\mathrm{C}_{5}$ are broken and the intramolecular proton migration rearrangement was generated. The fragment ion at $m / z 394$ was broken in the same way as M6, so it is presumed that M15 was the $\mathrm{N}$-demethylated metabolite of IM.

In addition, $\mathrm{M} 11\left(\mathrm{C}_{18} \mathrm{H}_{17} \mathrm{~N}_{5} \mathrm{O}\right)$, eluted at $9.50 \mathrm{~min}$, gave $\mathrm{a}[\mathrm{M}+\mathrm{H}]^{+}$at $m / z 320.1498(173$ Da less than that of IM). The
MS/MS spectra of M11 had a special peak at $m / z 278$, owing to the amide bond breaking (deacetylation), and the other $\mathrm{m} / z 261$ was $17 \mathrm{Da}$ lower than the fragment ion at $\mathrm{m} / z 278$ of M11 as a result of losing $\mathrm{NH}_{2}$, indicating that M11 is a metabolite of $\mathrm{N}$-acetylation after amide bond hydrolysis of IM.

The $[\mathrm{M}+\mathrm{H}]^{+}$ion of $\mathrm{M} 27\left(\mathrm{C}_{24} \mathrm{H}_{21} \mathrm{~N}_{5} \mathrm{O}\right)$ at $m / z 396.1818$ was $97 \mathrm{Da}$ lower than that of IM and eluted at $15.70 \mathrm{~min}$. The product ion at $m / z 378$ was formed by losing a molecular of $\mathrm{H}_{2} \mathrm{O}$ via the amide bond; thus, M27 was generated by removal of the 4-methyl-1-piperazinyl from IM. In the MS/MS spectra, M26 $\left(\mathrm{C}_{24} \mathrm{H}_{19} \mathrm{~N}_{5} \mathrm{O}_{2}\right)$ showed the molecular ion $[\mathrm{M}+\mathrm{H}]^{+}$at $m / z 410.1613$ and was eluted at $15.70 \mathrm{~min}$, which is $83 \mathrm{Da}$ less than that of M0. The fragment ion at $\mathrm{m} / z 392$ and the $m / z 378$ of M27 shared the same pathway of losing one molecular of $\mathrm{H}_{2} \mathrm{O}$ and $m / z 261$ fragment ions are generated via breakage between the $\mathrm{N}$ of the benzamide group and the benzene ring. Therefore, M26 may be a metabolite of formaldehyde generated from the methyl group at the $\mathrm{C}_{4}$ position of the benzene ring on the benzamide group of IM.

M17 $\left(\mathrm{C}_{26} \mathrm{H}_{24} \mathrm{~N}_{6} \mathrm{O}\right)$ exhibited a protonated molecule ion $[\mathrm{M}+\mathrm{H}]^{+}$at $m / z 437.2082$ and was eluted at $11.09 \mathrm{~min}$, which is $56 \mathrm{Da}$ less than that of IM. Fracture mode was the same as IM. The fragment ion $m / z 394$ was formed via rupture of 4methyl-1-piperazine group, indicating that 4-methyl-1piperazinyl undergoes $\mathrm{N}$-demethylation with simultaneous catalytic dehydrogenation. In addition, the loss of one 

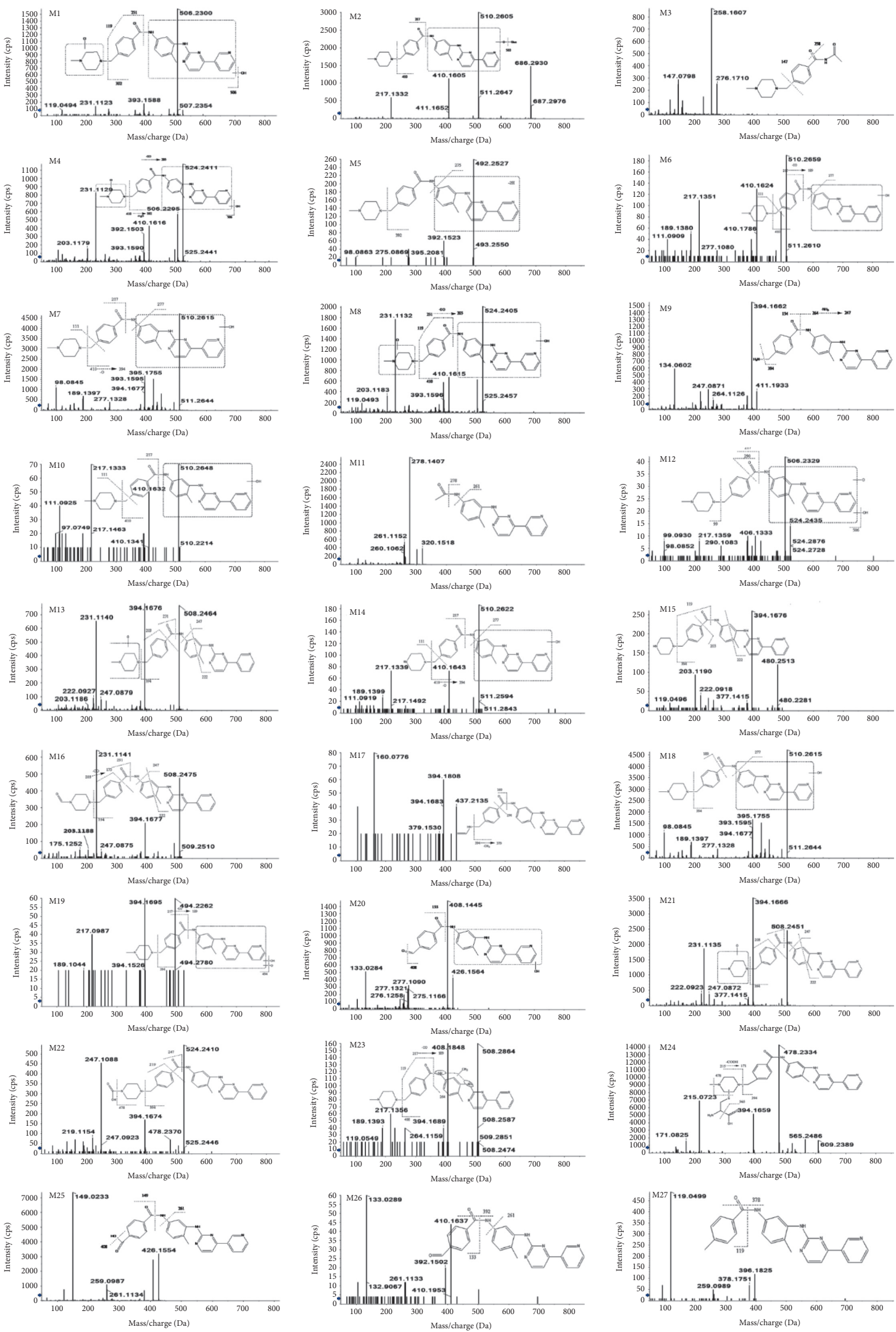

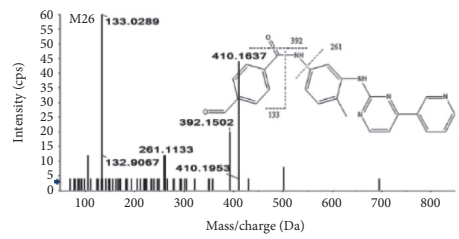

(b)

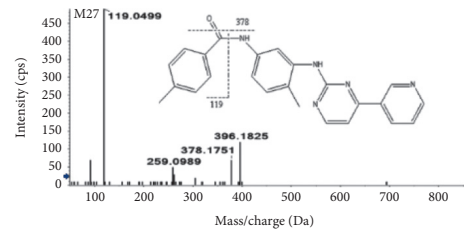

(c)

Figure 5: UHPLC-Q-TOF-MS/MS of all metabolites. 
molecule of methyl $\mathrm{CH}_{3}$ from the $m / z 394$ fragment ion resulted in the fragment ion of $m / z 379$, followed by $m / z 290$ through dehydrogenation of one molecule of the benzene ring. The fragment of $m / z 160$ was generated by the breakage of the amide bond after dehydrogenation of $\mathrm{C}_{3} \mathrm{H}_{5} \mathrm{~N}$, and it was predicted that M17 may be the dehydrogenation product of IM after dehydrogenation of one molecule of $\mathrm{C}_{3} \mathrm{H}_{5} \mathrm{~N}$ from the metabolite.

M5 $\left(\mathrm{C}_{30} \mathrm{H}_{32} \mathrm{~N}_{6} \mathrm{O}\right.$, eluted at $\left.7.47 \mathrm{~min}\right)$ and $\mathrm{M} 19$ $\left(\mathrm{C}_{29} \mathrm{H}_{30} \mathrm{~N}_{7} \mathrm{O}_{3}\right.$, eluted at $\left.11.54 \mathrm{~min}\right)$, showing the molecular ion $[\mathrm{M}+\mathrm{H}]^{+}$at $\mathrm{m} / z \quad 492.2508$ and 524.2397 , were $1 \mathrm{Da}$ different from that of IM. The metabolite lost hydrogen atom from carbonyl and $\mathrm{N}$ on phenylamino groups so that $\mathrm{m} / \mathrm{z}$ 392 of M5 appeared in the MS/MS spectra and another one $m / z 275$ fragment ion is the product of breakage of $\mathrm{N}$ and benzene ring of benzamide group. As a result, M5 was presumed to be a metabolite of the dehydrogenation of N-4methyl-3-[4-(3-pyridyl)-2-pyrimidine. The $m / z 494$ fragment ion produced by M19 was the prototype drug of IM. Therefore, it was considered to be the fragment ion of its broken substituted one-molecule hydroxyl and one-molecule carbonyl. The fragments of $m / z 189, \mathrm{~m} / z 217$, and $m / z$ 394 were formed in the same way as M6 and M7. Based on the above results, it was concluded that M19 was the metabolite of IM 4-methyl-3-[4-(3-pyridyl)-2-pyrimidine by losing one molecule of hydroxyl and one molecule of carbonyl-substituted metabolite.

M12 $\left(\mathrm{C}_{29} \mathrm{H}_{31} \mathrm{~N}_{7} \mathrm{O}_{3}\right)$ and M22 $\left(\mathrm{C}_{29} \mathrm{H}_{29} \mathrm{~N}_{7} \mathrm{O}_{3}\right)$ exhibited a molecular ion at $m / z 524.2409$ and $m / z 524.2396$, which are $21 \mathrm{Da}$ more than that of IM. In the MS/MS spectra of M12, $\mathrm{m} / z 506$ fragment ion was the fragment ion generated from the substituted metabolite by removing $\mathrm{H}_{2} \mathrm{O}$. Methyl pyridine ring $\left(\mathrm{C}_{4}\right.$ of 2 -aniline pyrimidine benzene ring) happens to break; then, the site on a pyrimidine ring of $\mathrm{C}_{1^{-}}$ $\mathrm{N}$ forms not only five-membered ring but also aminocarbonyl and $\mathrm{N}$ benzoyl break and, at the same time, produces $\mathrm{m} / z 290$ and $\mathrm{m} / z 217$. The structure of the 1 methylpiperazine group cracked the metabolite, resulting in the fragment ion $\mathrm{m} / \mathrm{z} 99$. As a result, M12 is molecular imatinib, a member of hydroxyl and carbonyl replacement metabolites (replacement occurred in 4-methyl-3-[4-(3pyridyl)-2-pyrimidine structures). The fragment of $\mathrm{m} / z 290$ was created via the breakage of the methyl group of $\mathrm{C}_{4}$ from the benzene ring of 2-anilinopyrimidine after the formation of a five-membered ring with $\mathrm{C}_{1}-\mathrm{N}$ of the pyrimidine ring and the break of the carbonyl group and $\mathrm{N}$ on the benzoylamino group, which also generates the $\mathrm{m} / z 217$ fragment ion, and the $m / z 99$ fragment ion produced from the break of the 1-methyl piperazinyl group break generated presumably M12, that is, the 4-methyl-3-[4-(3-pyridyl)-2-pyrimidine of IM with one molecule of hydroxyl and one molecule of carbonyl-substituted metabolite. The $m / z 478$ fragment ion of M22 was generated by N-demethylation in the prototype of IM, and the $m / z 247$ fragment ion further deamidates the remaining carbonyl $\mathrm{CO}$ to produce the $m / z 219$ fragment ion of M22. Therefore, it was presumed to be oxidized to carboxylic acid on N-methyl, and M22 was a metabolite of oxidation of methyl to carboxylic acid on N-methyl of IM.
3.2. Metabolite Analysis in Bile. Compared with the control group, 21 metabolites were detected in the bile. Moreover, 6 of them (M3, M9, M11, M17, M20, and M26) were newly discovered. The extracted ion chromatograms of all bile metabolites are shown in Figure 6. The chromatographic retention behavior of the metabolites, quasimolecular ions, and secondary fragment ions was comprehensively analyzed (Table 1). It was found that 12 of them were consistent with the metabolites in plasma, and the other 9 were different. Fragmental ions are shown in Figure 5.

$\mathrm{M} 1, \mathrm{M} 4$, and $\mathrm{M} 8$ shared the same formula $\left(\mathrm{C}_{29} \mathrm{H}_{30} \mathrm{~N}_{7} \mathrm{O}_{3}\right)$ with similar mass spectra and were eluted at the retention time of $9.10,6.36$, and $7.22 \mathrm{~min}$. They showed molecule ions $[\mathrm{M}+\mathrm{H}]^{+}$of $\mathrm{m} / z 524.2412,524.2414$, and 524.2406, respectively. The loss of $30 \mathrm{Da}$ can be detected in the MS/MS spectrum. It was speculated that they were the product of one molecule of hydroxyl substitution and one molecule of carbonyl substitution of IM.

M20 and M25 $\left(\mathrm{C}_{24} \mathrm{H}_{20} \mathrm{~N}_{5} \mathrm{O}_{3}\right)$ were eluted at $13.20 \mathrm{~min}$ and $11.83 \mathrm{~min}$. They showed molecular ion $[\mathrm{M}+\mathrm{H}]^{+}$at $\mathrm{m} / z$ 426.1568 and 426.1582 , which were $68 \mathrm{Da}$ less than IM. The neutral loss of $18 \mathrm{Da}\left(\mathrm{H}_{2} \mathrm{O}\right)$ was obtained between the ions $\mathrm{m} / z$ 426 and 408. Fragment ion at $m / z 261$ was the product of the cleavage of $\mathrm{N}$ and the benzene ring on the benzamide. Therefore, it was speculated that the methyl group of 4methylbenzamide was oxidized to a carboxylic acid. Based on the above results, it was inferred that M25 was a metabolite of IM depleted 4-methyl-1-piperazinyl carboxylic acid. The fragment ion at $m / z 133$ was generated by the CO-N cleavage of the amide bond of benzamide after M20 carbonyl substitution. The fragmentation of other ions was the same as the analysis. According to the metabolic law, it was speculated that the methyl group of 4-methylbenzamide was oxidized to aldehyde. Thus, it was inferred that M20 was formed by removal of $\mathrm{N}$-[4methyl-3-[4-(3-pyridyl) from 4-methyl-1-piperazinylbenzamide on IM-2-pyrimidinyl]amino]phenyl, one molecule of hydroxyl substitution, and 4-methyl benzamide part of the methyl oxidation to the metabolite of aldehyde.

M9 $\left(\mathrm{C}_{24} \mathrm{H}_{23} \mathrm{~N}_{6} \mathrm{O}\right)$ was eluted at $9.41 \mathrm{~min}$, and the $[\mathrm{M}+\mathrm{H}]^{+}$at $m / z 411.1931$ was $83 \mathrm{Da}$ less than IM. The fragment ion at $m / z 394$ was obtained by the loss of $\mathrm{NH}_{3}$, and $\mathrm{m} / z 134$ was the amide bond $\mathrm{CO}-\mathrm{N}$ cleavage of benzamide after the loss of $\mathrm{C}_{5} \mathrm{H}_{9} \mathrm{~N}$. Therefore, it was an IM metabolite after losing 4-methyl-1-piperazinyl $\mathrm{C}_{5} \mathrm{H}_{9} \mathrm{~N}$.

M3 $\left(\mathrm{C}_{15} \mathrm{H}_{22} \mathrm{~N}_{3} \mathrm{O}_{2}\right)$, M2 $\left(\mathrm{C}_{35} \mathrm{H}_{40} \mathrm{~N}_{7} \mathrm{O}_{8}\right)$, and M24 $\left(\mathrm{C}_{32} \mathrm{H}_{33} \mathrm{~N}_{8} \mathrm{O}_{3} \mathrm{~S}\right)$ were phase II metabolites of IM, which are eluted at $6.78 \mathrm{~min}, 6.45 \mathrm{~min}$, and $12.68 \mathrm{~min}$, respectively. They showed molecular ion $[\mathrm{M}+\mathrm{H}]^{+}$at $\mathrm{m} / z$ 276.1708, 686.2936, and 609.2383. M3 was 318 Da less than IM. The product ion at $m / z 258$ implied the loss of $\mathrm{H}_{2} \mathrm{O}$. The loss of 4methyl-1-piperazinyl was obtained between $\mathrm{m} / z 258$ and $\mathrm{m} /$ $z$ 147. M3 was an $\mathrm{N}$-acetylation metabolite after IM amide bond hydrolysis. M2 was $192 \mathrm{Da}$ more than IM. The characteristic fragment ion at $\mathrm{m} / z 686$ generated the ion at $\mathrm{m} / z 510$ by the loss of glucuronic acid molecule $(\mathrm{m} / z$ 176). It was speculated that M2 may be the glucuronic acid conjugate after partial oxidation of N-4-methyl-3-[4-(3-pyridinyl)-2-pyrimidinyl] amino]phenyl of imatinib benzamide. M24 was $115 \mathrm{Da}$ more than IM. The fragment ions at $\mathrm{m} / z$ 

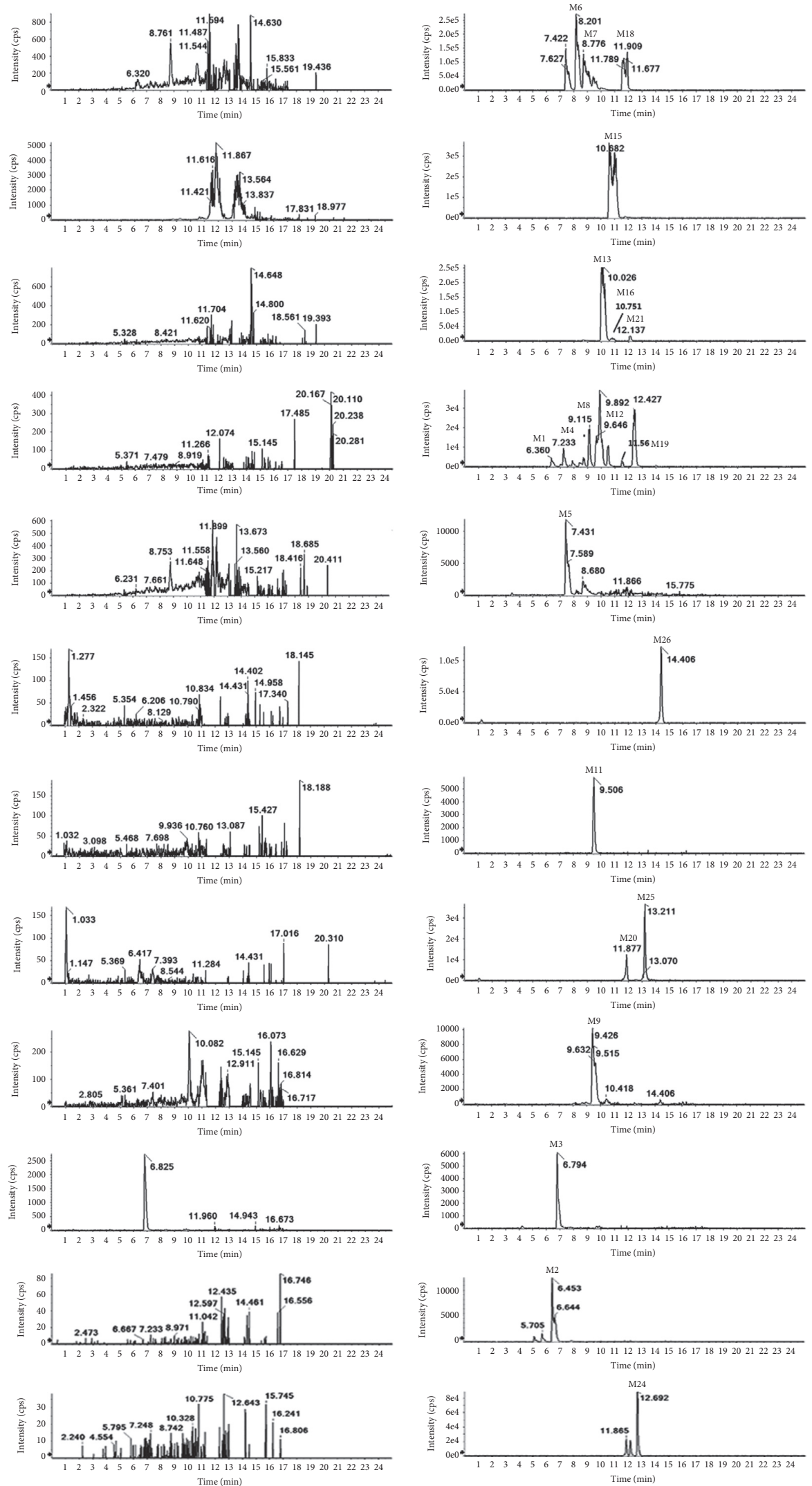

(a)

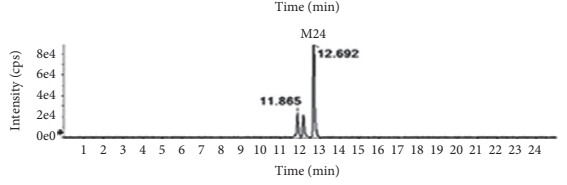

(b)

FIGURE 6: Extracted ion chromatograms (XIC) for metabolites in rats: (a) in blank bile sample; (b) in bile sample after an oral administration of IM. 

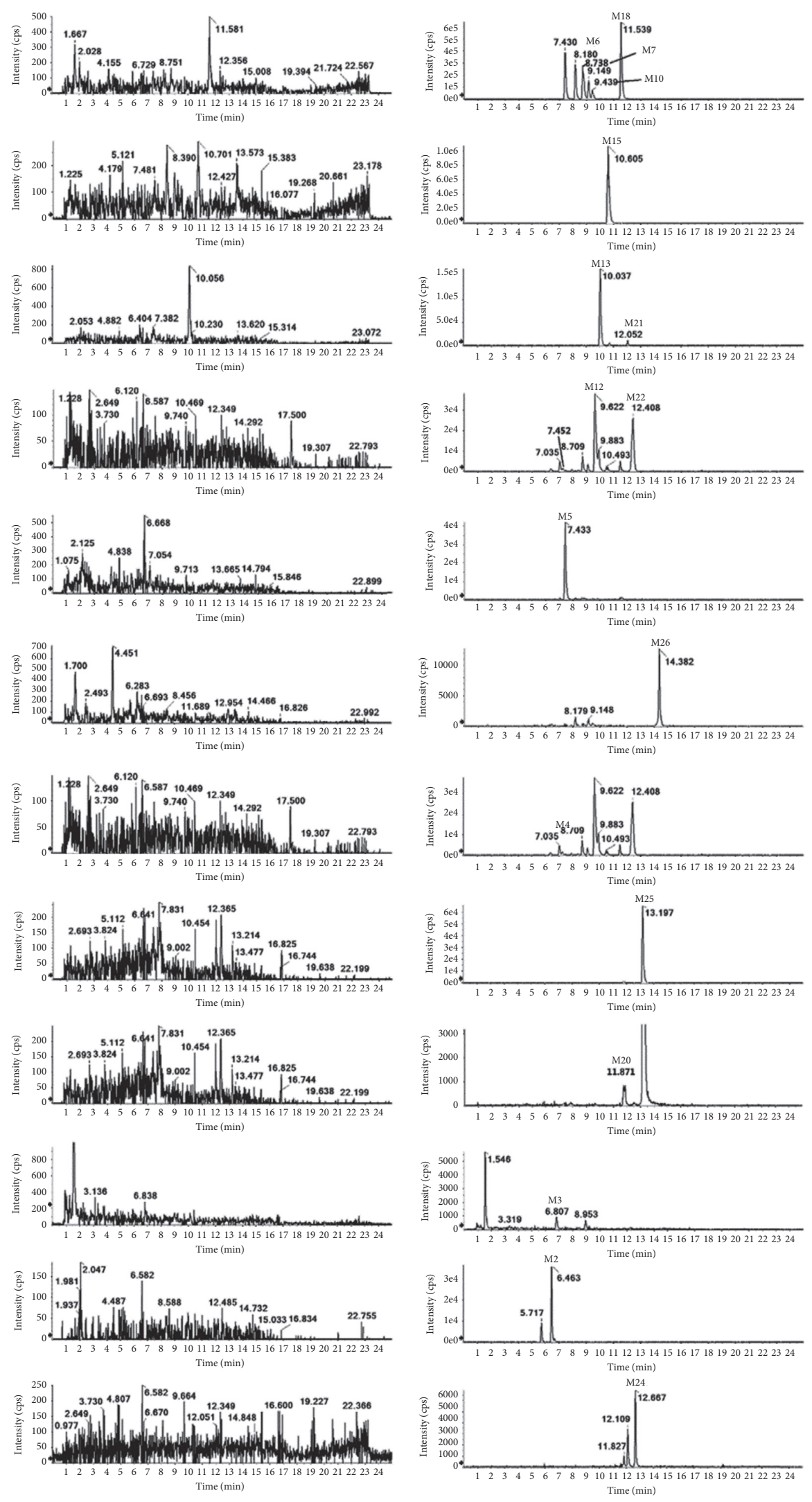

(a)

(b)

Figure 7: Extracted ion chromatograms (XIC) for metabolites in rats: (a) in blank urine sample; (b) in urine sample after an oral administration of IM. 

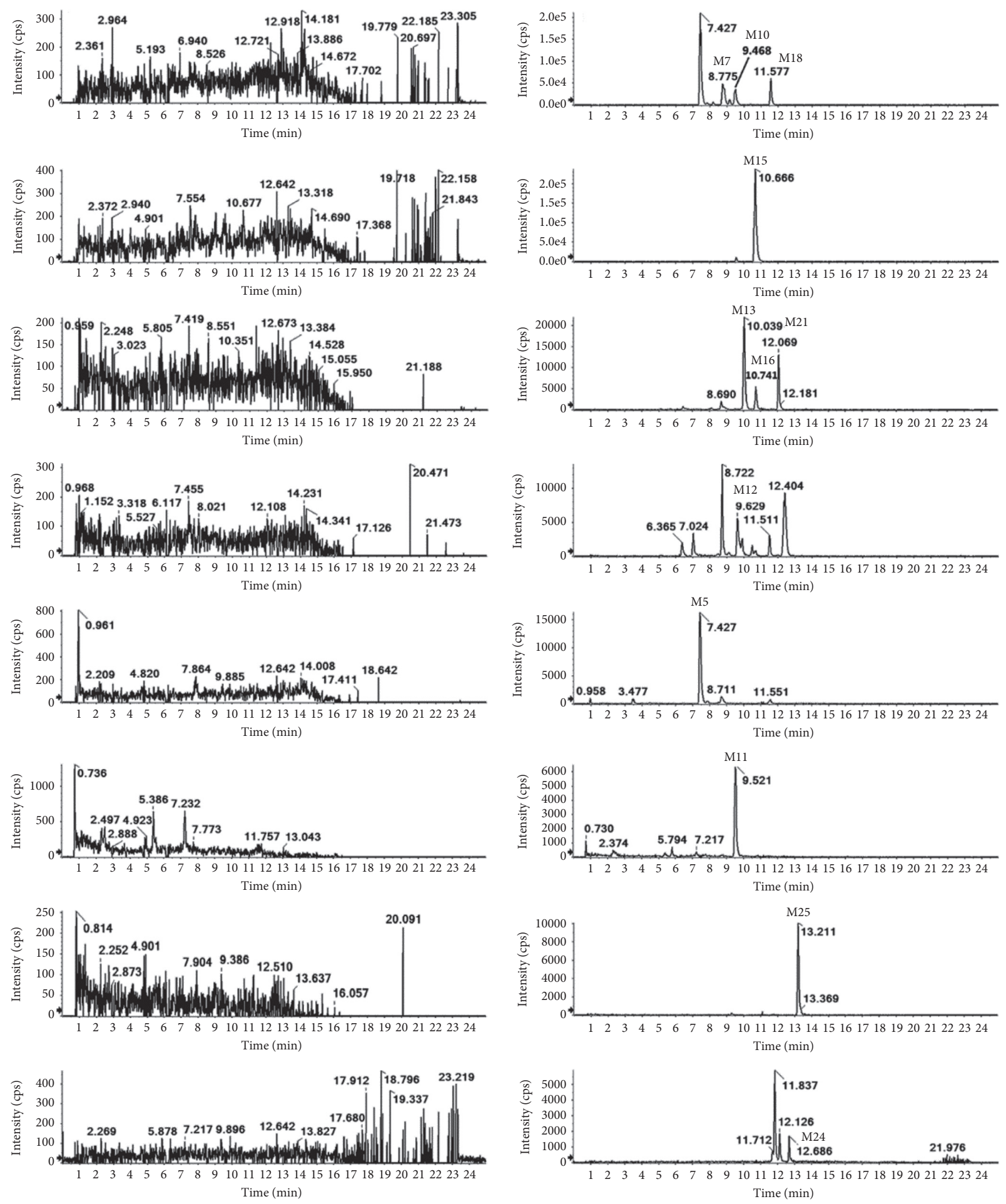

(a)

(b)

FIgURE 8: Extracted ion chromatograms (XIC) for metabolites in rats: (a) in blank feces sample; (b) in feces sample after an oral administration of IM.

394 and $m / z 215$ are generated by the cleavage of benzamido benzyl and piperazine. The fragment ion at $m / z 215$ was composed of cysteine and 4-methyl-1-piperazine. M24 was speculated to be the metabolite of 4-methyl-1-piperazinyl with cysteine binding.
3.3. Metabolite Analysis in Urine. Compared with blank urine samples, in addition to the IM prototype drug, 18 metabolites were detected. Ion chromatography of all urine metabolites extracted is shown in Figure 7. Comprehensive analysis of chromatographic retention behavior, 


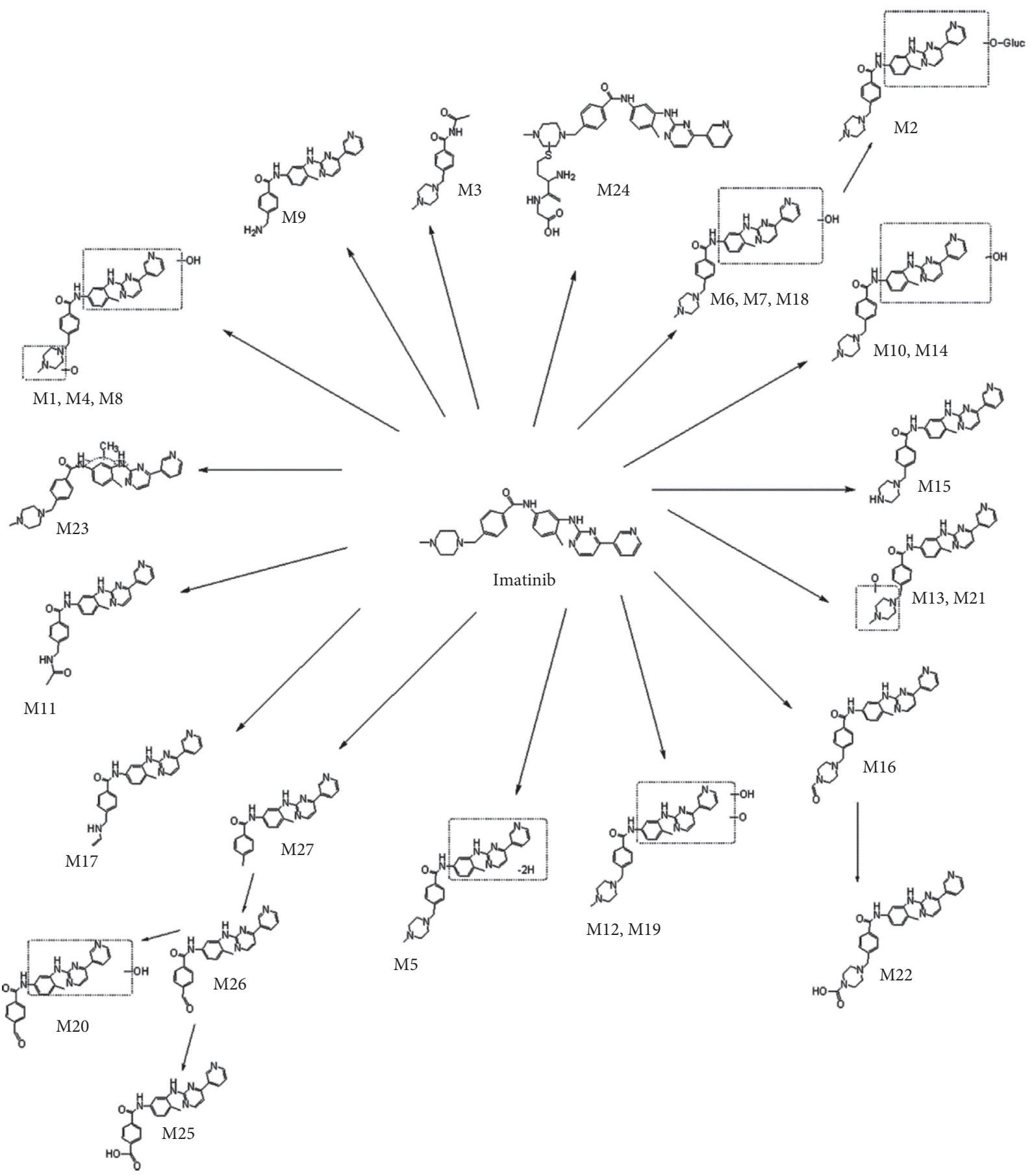

FIGURE 9: Proposed metabolic pathways of IM in rats.

quasimolecular ions, and secondary fragments ions are shown in Table 1.

3.4. Metabolite Analysis in Feces. Compared with blank stool samples, in addition to the IM prototype drug, 12 compounds were also detected. The extracted ion chromatograms of all feces metabolites are shown in Figure 8. Comprehensive analysis of chromatographic retention behavior, quasimolecular ions, and secondary fragments ions is presented in Table 1.
3.5. Metabolic Pathways of IM in Rats. In summary, the UHPLC-Q-TOF-MS/MS method was used to study the metabolism of IM in rats. A total of 27 metabolites were found, including 22 phase I metabolites and 5 phase II metabolites. The phase I metabolic pathways contained hydroxylation, oxidation, catalytic dehydrogenation, and dealkylation; the phase II metabolic pathways were $\mathrm{N}$-acetylation, methylation, cysteine binding reactions, and glucuronidation. These metabolic pathways may also cross-link each other to generate secondary metabolites. Based on the above results, the main metabolic pathways of IM in rats are summarized in Figure 9. 


\section{Discussion}

In the results of this experiment, M1-M2, M4-M8, M10, M12M16, M18-M19, M21, and M24-M25 were previously reported metabolites of IM. Among them, the characteristic fragment ions and structures of M6, M7, M10, M14, M15, and M18 were consistent with those of M3, M8, M5, M6, $\mathrm{N}$-demethyl metabolite, and M7 in the actual test results of Marull and Rochat [18]. In this experiment, the structures of M13, M21, and M25 were consistent with the previously reported structures of M29.6 and APG050 and M42.2 [23]. The oxides and dioxides in the results of Friedecky et al. (metabolites 59-61 and 65-74) may be consistent with M16 and M1, M4, M8, M12, and M19 in this study because they shared the same molecular formula and weight [20]. M5 was consistent with the previously reported dissociation products of M519 B because they had the same characteristic fragment ions and chemical structures [19]. M24 was also similar to the reported M609, and they all have fragment ions at $\mathrm{m} / z 215, \mathrm{~m} /$ $z$ 394, $\mathrm{m} / z$ 478, and $\mathrm{m} / z 565$ [24]. In addition, the experimental results of M2 may be the same as metabolite No. 25 of Rochat et al. [25], but they did not provide complete characteristic fragments ion and structural formula. Therefore, new content was added to this study. With regard to the effect of IM metabolites, N-demethylated metabolites of IM (M15 in this experiment) were the main metabolites of IM, although they had similar effects. However, some studies have shown that the pharmacological activity of N-demethyl IM was three times lower than that of IM [26]. Mlejnek et al. also found that $\mathrm{N}$-demethyl IM had almost no therapeutic effect on CML through K562 cell experiments [17]. In addition, some studies have shown that some metabolic compounds, especially highly demethylated and sulfur-containing compounds (M15 and M24 in this experiment) may be related to IM adverse reactions $[24,26]$.

With regard to the newly discovered IM metabolites in this experiment, M22 is an IM metabolite with a carboxyl group, which was widely used in drug design and synthesis and was often used to form pharmacophore of various drugs. In addition, this group was reported to play a key role in the interaction between drugs and targets [27]. M3 and M11 were newly discovered $\mathrm{N}$-acetylated metabolites in this experiment. Studies have shown that acetylated compounds can induce apoptosis in CML cells (k562) and IM-resistant CML cells (IR-K562). Therefore, these metabolites may have the potential of value for the drug development industry [28]. M23 was a newly discovered $\mathrm{N}$-methylated metabolite. It has been reported that methylation biomarkers were closely related to drug resistance, and it may help with the study on drug resistance of CML [29]. M9 and M27 were the metabolites of dealkylation. Studies showed that the dealkylation metabolites of TKI had the same effect as the original drug. Therefore, M9 and M27, as newly discovered IM dealkylation metabolites, may also have the potential drug activity [21]. M26 and M20 were metabolites with aldehyde groups, which can lead to inactivation of cytochrome P450, drug interaction (DDI), and hepatotoxicity. They may provide a new way to investigate the toxicity of TKI drugs [16]. M17 was the first-phase metabolite of $\mathrm{N}$-demethylation and catalytic dehydrogenation, and it was a new metabolite discovered for the first time.

The metabolites of IM and the fragment ions of IM were mainly produced by the cleavage of the $\mathrm{C}-\mathrm{N}$ bond at the amide site, and the metabolic position of IM metabolites was determined by the increase or decrease of the molecular weight of the corresponding fragment ions. For example, $\mathrm{N}$-oxidized metabolites tend to lose $\mathrm{O}$ on $\mathrm{N}$ during mass spectrometry cleavage, thus forming fragment ions lacking $16 \mathrm{Da}$. Therefore, the type and location of metabolic reaction can be determined by comparing the changes of the ion-to-nucleus ratio of fragments. In addition, in the analysis of IM and its phase II metabolites by two-phase full scan mass spectrometry, it was found that the glucuronic acid conjugate and cysteine conjugate first removed the binding group and obtained the corresponding mother nucleus.

\section{Conclusions}

In this study, the metabolic spectrum of IM in rats was studied using UHPLC-Q-TOF-MS/MS technique. 27 IM metabolites (18 known and 9 unknown) were found in plasma, bile, urine, and feces, including 18 in plasma, 21 in bile, 18 in urine, and 12 in feces. There were 22 metabolites in phase I. M6, M7, M10, M14, and M18 were formed by hydroxylation. M13, M16, M21, and M26 were formed by oxidation, and M5 was formed by catalytic dehydrogenation. M9, M15, and M27 were generated by dealkylation metabolism. M1, M4, M8, M12, M17, M19, M20, M22, and M25 were produced by cross-reaction. There were five phase II metabolites, M2 was formed by glucuronic acid-binding reaction, and M23 is through methylation. M11 and M3 were formed by N-acetylation and M24 was due to the cysteine binding reaction. IM and its phase I metabolites can be combined with endogenous substances to greatly improve the water solubility of metabolites and the level of drug excretion. However, the methylation metabolite M23 (II phase) of IM was on the contrary. Under the action of methylation, the methylated compound S-adenosyl methylthiamine (SAM) was used as a cofactor. After being catalyzed by methyltransferase, methyl was transferred to the $\mathrm{O}, \mathrm{S}, \mathrm{N}$ atoms of the substrate to form a less polar product, resulting in a decrease in the water solubility of the metabolite, making it difficult to be excreted. Since more metabolites were found in bile and urine, it was suggested that IM and its metabolites rely on bile and urine for metabolism and excretion.

\section{Data Availability}

All data generated or analyzed during this study are included within this article.

\section{Conflicts of Interest}

The authors declare that there are no conflicts of interest regarding the publication of this paper. 


\section{References}

[1] E. D. Tetzlaff and M. P. Davey, "Optimizing adherence to adjuvant imatinib in gastrointestinal stromal tumor," Journal of the Advanced Practitioner in Oncology, vol. 4, no. 4, pp. 238-250, 2013.

[2] N. Iqbal and N. Iqbal, "Imatinib: a breakthrough of targeted therapy in cancer," Chemotherapy Research and Practice, vol. 2014, Article ID 357027, 2014.

[3] Y. Zhu and S. Qian, "Clinical efficacy and safety of imatinib in the management of $\mathrm{Ph}+$ chronic myeloid or acute lymphoblastic leukemia in Chinese patients," OncoTargets and Therapy, vol. 7, pp. 395-404, 2014.

[4] D. G. Savage and K. H. Antman, "Imatinib mesylate: a new oral targeted therapy," New England Journal of Medicine, vol. 346, no. 9, pp. 683-693, 2002.

[5] B. J. Druker, S. Tamura, E. Buchdunger et al., "Effects of a selective inhibitor of the Abl tyrosine kinase on the growth of Bcr-Abl positive cells," Nature Medicine, vol. 2, no. 5, pp. 561-566, 1996.

[6] L. Ma, Y. Shan, R. Bai et al., "A therapeutically targetable mechanism of BCR-ABL-independent imatinib resistance in chronic myeloid leukemia," Science Translational Medicine, vol. 6, no. 252, pp. 121r-252r, 2014.

[7] J. Hentschel, I. Rubio, M. Eberhart et al., "BCR-ABL- and Rasindependent activation of Raf as a novel mechanism of Imatinib resistance in CML," International Journal of Oncology, vol. 39, no. 3, pp. 585-591, 2011.

[8] H. Schran, B. Peng, and P. Lloyd, "Clinical pharmacokinetics of imatinib," Clinical Pharmacokinetics, vol. 44, no. 9, pp. 879-894, 2005.

[9] G. N. Kumar and S. Surapaneni, "Role of drug metabolism in drug discovery and development," Medicinal Research Reviews, vol. 21, no. 5, pp. 397-411, 2001.

[10] R. E. White, "High-throughput screening in drug metabolism and pharmacokinetic support of drug discovery," Annual Review of Pharmacology and Toxicology, vol. 40, no. 1, pp. 133-157, 2000.

[11] R. E. White, "Short- and long-term projections about the use of drug metabolism in drug discovery and development," Drug Metabolism and Disposition: The Biological Fate of Chemicals, vol. 26, no. 12, pp. 1213-1216, 1998.

[12] M. Pirmohamed, "Drug metabolism," Medicine, vol. 36, no. 7, pp. 355-359, 2008.

[13] A. Fura, Y.-Z. Shu, M. Zhu, R. L. Hanson, V. Roongta, and W. G. Humphreys, "Discovering drugs through biological transformation: role of pharmacologically active metabolites in drug discovery," Journal of Medicinal Chemistry, vol. 47, no. 18, pp. 4339-4351, 2004.

[14] J. H. Lin and A. Y. Lu, "Role of pharmacokinetics and metabolism in drug discovery and development," Pharmacological Reviews, vol. 49, no. 4, pp. 403-449, 1997.

[15] I. Hrynchak, E. Sousa, M. Pinto, and V. M. Costa, "The importance of drug metabolites synthesis: the case-study of cardiotoxic anticancer drugs," Drug Metabolism Reviews, vol. 49, no. 2, pp. 158-196, 2017.

[16] M.-N. Paludetto, J.-L. Stigliani, A. Robert et al., "Involvement of pazopanib and sunitinib aldehyde reactive metabolites in toxicity and drug-drug interactions in vitro and in patient samples," Chemical Research in Toxicology, vol. 33, no. 1, pp. 181-190, 2020.

[17] P. Mlejnek, P. Dolezel, E. Faber, and P. Kosztyu, "Interactions of $\mathrm{N}$-desmethyl imatinib, an active metabolite of imatinib, with P-glycoprotein in human leukemia cells," Annals of Hematology, vol. 90, no. 7, pp. 837-842, 2011.

[18] M. Marull and B. Rochat, "Fragmentation study of imatinib and characterization of new imatinib metabolites by liquid chromatography-triple-quadrupole and linear ion trap mass spectrometers," Journal of Mass Spectrometry, vol. 41, no. 3, pp. 390-404, 2006.

[19] A. C. Li, E. Yu, S. C. Ring, and J. P. Chovan, "Structural identification of imatinib cyanide adducts by mass spectrometry and elucidation of bioactivation pathway," Rapid Communications in Mass Spectrometry, vol. 28, no. 1, pp. 123-134, 2014.

[20] D. Friedecký, K. Mičová, E. Faber, M. Hrdá, J. Široká, and T. Adam, "Detailed study of imatinib metabolization using high-resolution mass spectrometry," Journal of Chromatography $A$, vol. 1409, pp. 173-181, 2015.

[21] R. S. Obach, "Pharmacologically active drug metabolites: impact on drug discovery and pharmacotherapy," Pharmacological Reviews, vol. 65, no. 2, pp. 578-640, 2013.

[22] A. Fura, "Role of pharmacologically active metabolites in drug discovery and development," Drug Discovery Today, vol. 11, no. 3-4, pp. 133-142, 2006.

[23] H.-P. Gschwind, U. Pfaar, F. Waldmeier et al., "Metabolism and disposition of imatinib mesylate in healthy volunteers," Drug Metabolism and Disposition, vol. 33, no. 10, pp. 15031512, 2005.

[24] I. Vrobel, D. Friedecký, E. Faber et al., "Novel sulphurcontaining imatinib metabolites found by untargeted LCHRMS analysis," European Journal of Pharmaceutical Sciences, vol. 104, pp. 335-343, 2017.

[25] B. Rochat, A. Fayet, N. Widmer et al., "Imatinib metabolite profiling in parallel to imatinib quantification in plasma of treated patients using liquid chromatography-mass spectrometry," Journal of Mass Spectrometry, vol. 43, no. 6, pp. 736-752, 2008.

[26] P. W. Manley, "Investigations into the potential role of metabolites on the anti-leukemic activity of imatinib, nilotinib and midostaurin," CHIMIA International Journal for Chemistry, vol. 73, no. 7-8, pp. 561-570, 2019.

[27] C. Ballatore, D. M. Huryn, and A. B. Smith III, "Carboxylic acid (bio) isosteres in drug design," ChemMedChem, vol. 8, no. 3, pp. 385-395, 2013.

[28] S.-H. Chen, J.-M. Chow, Y.-Y. Hsieh et al., "HDAC1, 2 knockout and HDACi induced cell apoptosis in imatinib-resistant K562 cells," International Journal of Molecular Sciences, vol. 20, no. 9, p. 2271, 2019.

[29] R. I. You, C. L. Ho, H. M. Hung, Y.-F. Hsieh, J.-C. Ju, and T.-Y. Chao, "Identification of DNA methylation biomarkers inimatinib-resistant chronic myeloid leukemia cells," Genomic Medicine Biomarkers \& Health Sciences, vol. 4, no. 1-2, pp. 12-15, 2012. 